\title{
Comprovação anatomopatológica da presença de tecido vascular e nervoso evidenciado à ecografia como eco tangencial ao descolamento de coróide: relato de dois casos
}

\author{
Histopathologic confirmation of vascular and nervous tissue identified on \\ ultrasound as an tangential image to choroidal detachment: report of two cases
}

\author{
Eduardo F.Marback ${ }^{1}$ \\ Fernanda Fernandes Pereira ${ }^{2}$ \\ Ricardo Danilo Chagas de Oliveira ${ }^{3}$ \\ Cláudia Galvão ${ }^{4}$ \\ Roberto L.Marback ${ }^{5}$
}

\section{RESUMO}

São apresentados dois casos de descolamento de coróide em olhos com endoftalmite submetidos a enucleação. O estudo anatomopatológico permitiu identificar a presença de tecido vascular e nervoso interpondo-se entre a esclera e coróide deslocada, como havia sido evidenciado pela ecografia.

Descritores: Coróide/patologia; Coróide/ultrassonografia; Hemorragia da coróide; Doenças da coróide; Relatos de casos

\section{INTRODUÇÃ̃O}

O descolamento de coróide pode ser classificado em exsudativo ou hemorrágico. Está associado a uma série de condições que levam à hipotonia e inflamação, como trauma acidental, cirurgias antiglaucomatosas e perfuração ocular ${ }^{(1-3)}$. Outro fator associado ao descolamento de coróide é a dificuldade de retorno venoso existente na nanoftalmia. No trauma, acidental ou cirúrgico, pode ainda acontecer rotura de um vaso coroidal e acúmulo de sangue no espaço supracoroidal, levando ao descolamento hemorrágico da coróide. Descolamentos de conteúdo misto, ou um descolamento inicialmente exsudativo que evolui para o tipo hemorrágico, também podem ser encontrados ${ }^{(1,3-5)}$.

O exame complementar mais utilizado para a comprovação do diagnóstico de descolamento de coróide é a ecografia ${ }^{(3,6-7)}$. Neste, o descolamento de coróide classicamente apresenta-se como eco membranáceo, de refletividade alta e em duplo pico, com mobilidade reduzida ou ausente, formato cupuliforme, usualmente iniciando-se na extrema periferia e prolongando-se até o equador ${ }^{(3,6-7)}$. Nos descolamentos exsudativos, o espaço supracoroidal é hipoecóico, já nos casos hemorrágicos e mistos, pode-se identificar ecos puntiformes móveis, de refletividade variável, a depender da quantidade de sangue presente. Um achado que ajuda a firmar o diagnóstico de descolamento de coróide, é a presença de eco membranáceo tangencial à coróide descolada e unindo-a à esclera ${ }^{(3,6-7)}$. Tal imagem é clinicamente interpretada como tecido vascular ou nervoso ${ }^{(6-7)}$. Entretanto, não encontramos na literatura pesquisada a correlação anatomopatológica deste achado com o quadro ecográfico ${ }^{(2-5)}$.

O objetivo deste trabalho é relatar dois casos de descolamento de coróide no qual foi possível realizar a correlação entre o aspecto ecográfico e anatomo- 
812 Comprovação anatomopatológica da presença de tecido vascular e nervoso evidenciado à ecografia como

eco tangencial ao descolamento de coróide: relato de dois casos

patológico, com a comprovação da presença de tecido vascular e nervoso tangencial ao descolamento de coróide.

\section{APRESENTAÇÃO DOS CASOS}

\section{Caso 1}

Paciente masculino, 73 anos, admitido com quadro de endoftalmite tardia após facectomia no olho direito (OD). Realizou explante da lente intraocular, com cultura positiva para fungos filamentosos, cuja espécie não foi possível identificar. A despeito do tratamento específico sistêmico, enquanto aguardava vitrectomia, evoluiu com hipotonia e descolamento seroso de coróide comprovado por ecografia, na qual foi também evidenciada a presença de eco tangencial à esclera e coróide descolada (Figura 1 - A e B). Diante do péssimo prognóstico visual e do início de toxicidade sistêmica à anfotericina $\mathrm{B}$, foi realizada enucleação do globo ocular.

À macroscopia da peça cirúrgica havia descolamento da coróide com aparente presença de tecido vascular interpondo-se entre a esclera e coróide descolada (Figura 1C). À microscopia identificou-se grande processo inflamatório intraocular, com a presença de fungos exibindo aspecto morfológico sugestivo de Aspergillus sp. Foi possível também confirmar a natureza vascular do tecido interposto entre a coróide e esclera visto pela ultrassonografia e macroscopia (Figura 1D).

\section{Caso 2}

Paciente masculino, 80 anos, encaminhado com história de tratamento para úlcera corneana nos últimos 15 dias após a remoção de um corpo estranho no olho esquerdo (OE). Relatava que o corpo estranho foi removido por ele mesmo, utili-
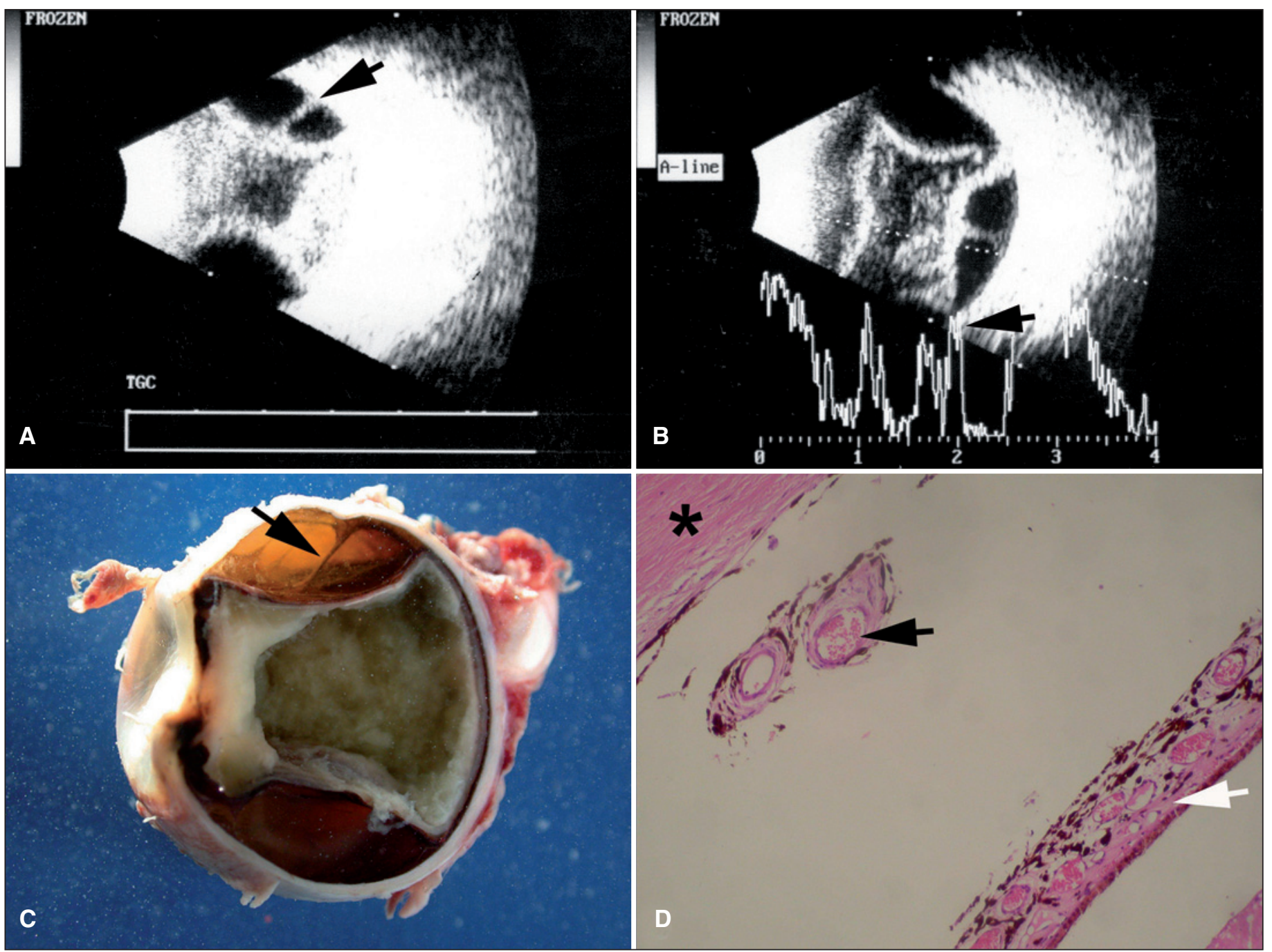

Figura 1 - A) Ecografia em modo B, corte longitudinal. Imagem compatível com descolamento de coróide com eco membranáceo interpondose entre esclera e coróide (seta); B) Ecografia em modo A e B, corte transversal. Presença de eco em duplo pico, característico do descolamento de coróide (seta); C) Macroscopia. Observa-se coróide descolada com tecido vascular correspondente à imagem ultrassonográfica (seta); D) Microfotografia. Comprovação do tecido vascular visto à ultrassonografia e macroscopia. Esclera (asterisco), tecido vascular (seta negra), coróide (seta branca) (hematoxilina e eosina). 

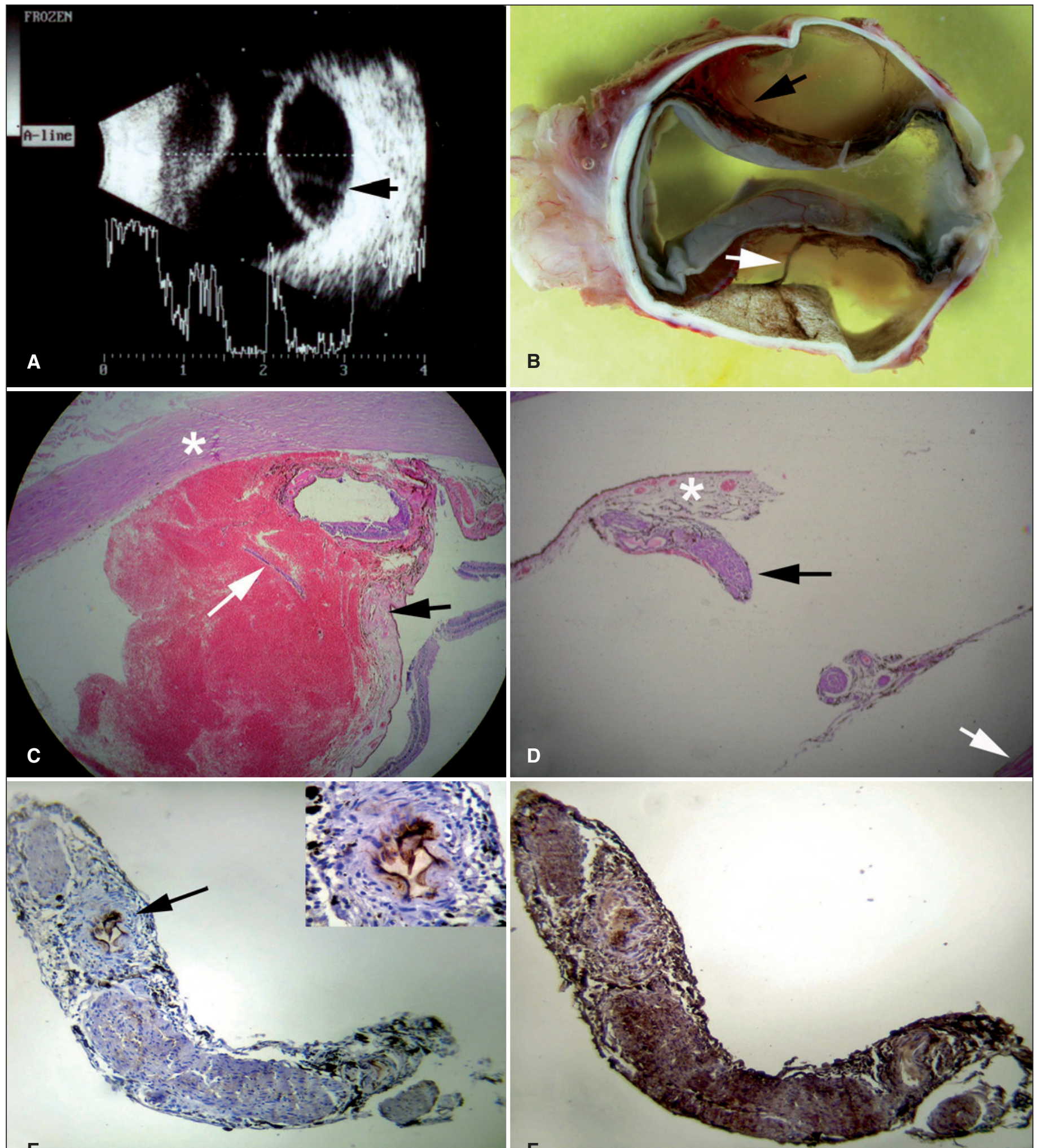

E

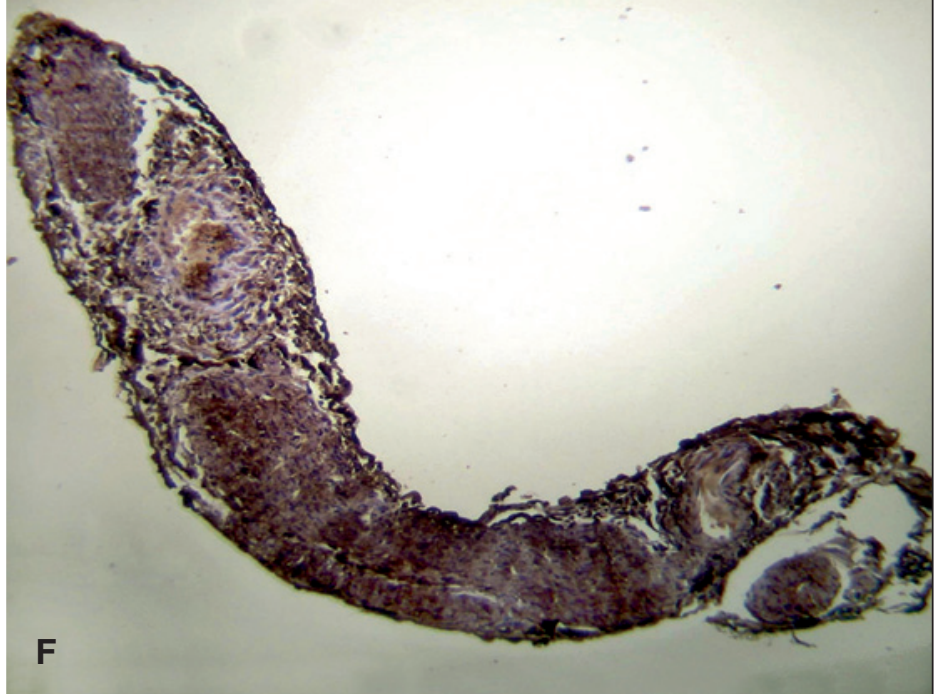

Figura 2 - A) Ultrassonografia em modo A e B. Imagem compatível com descolamento de coróide com eco membranáceo tangencial à esclera e coróide (seta); B) Macroscopia. Observa-se coróide descolada com feixes de tecido entre esta e a esclera (setas); C) Microfotografia. Comprovação do tecido nervoso (seta branca) interpondo-se entre a esclera (asterisco) e coróide (seta negra) (hematoxilina e eosina); D) Microfotografia. Tecido vascular e nervoso (seta negra) tangencial à esclera (seta branca) e coróide (asterísco) (hematoxilina e eosina); E) Estudo imuno-histoquímico com CD 34 evidenciando área de tecido vascular (seta), melhor vista no detalhe; F) Estudo imuno-histoquímico com NSE comprovando natureza nervosa do tecido. 
zando "pinça de sobrancelha". Ao exame apresentava OE sem percepção luminosa, presença de muita secreção purulenta e úlcera de córnea com extensa perfuração tamponada pela íris. $\mathrm{O}$ aspecto ecográfico era típico de descolamento total de coróide, com a presença de eco tangencial unindo coróide à esclera (Figura 2A). Foi submetido à enucleação do OE.

$\mathrm{O}$ estudo anatomopatológico revelou à macroscopia, extensa perfuração corneana, tamponada por íris, afacia, turvação do vítreo anterior, presença de descolamento de coróide com hemorragia focal e a presença de tecido interpondo-se entre a coróide descolada e esclera em pelo menos 3 pontos (Figura 2B). À microscopia, havia sinais de endoftalmite com processo inflamatório do tipo agudo, sendo que o tecido interposto entre a coróide e a esclera teve sua natureza vascular e nervosa comprovada por estudo imuno-histoquímico com anticorpos anti-CD 34, específico para endotélio vascular e NSE - neuron specific enolase (Dako -Dinamarca), específico para tecido nervoso (Figura 2 - $\mathrm{C} \mathrm{e} \mathrm{F}$ ).

\section{DISCUSS ÃO}

O espaço supracoroidal é um espaço virtual. Em condições normais, o volume de líquido presente neste espaço é inferior a $10 \mu \mathrm{l}^{(1)}$. Quando este espaço é preenchido por líquido de exsudação ou sangue torna-se real, sendo limitado anteriormente pelo esporão escleral e posteriormente pelo nervo óptico. Entretanto, existem pontos de aderência nas ampolas das veias vorticosas e nos vários vasos e nervos que penetram o tecido uveal a partir da esclera ${ }^{(3-5)}$.

A fisiopatologia do descolamento de coróide envolve a efusão de líquido causada por inflamação ou hemorragia. O descolamento exsudativo, resultante do ingurgitamento dos vasos de coróide e corpo ciliar, pode progredir para tração e rotura das artérias ciliares longas, transformando o descolamento seroso em hemorrágico, quando isto acontece na presença de solução de continuidade de esclera ou córnea (cirurgia ou trauma), pode ocorrer a extrusão do conteúdo ocular, caracterizando a hemorragia expulsiva ${ }^{(3-5)}$.

É possível encontrar descrição anatomopatológica de tecido vascular e nervoso, com aderência à esclera e coróide, interpondo-se tangencialmente entre estas duas túnicas na even- tualidade de um descolamento de coróide ${ }^{(2-5)}$. Também é possível encontrar referência a estes tecidos compondo a imagem de eco tangencial entre esclera e coróide, visto à ecografia ${ }^{(6-7)}$. Entretanto, não encontramos na literatura pesquisada a comprovação da correlação entre este aspecto ecográfico e o achado anatomopatológico dos tecidos que compõem aquela imagem.

Neste relato, apresentamos dois casos de descolamento de coróide extenso, secundários à endoftalmite infecciosa. Devido à progressão da doença, em olhos sem possibilidade de recuperação funcional, foi realizada enucleação em ambos. O estudo anatomopatológico destes dois olhos permitiu comprovar que a imagem tangencial à coróide e esclera, presente ao exame ecográfico de ambos os casos, é realmente formada por tecido vascular ou nervoso.

\section{ABSTRACT}

Two cases of endophthalmitis with choroidal detachment submitted to enucleation are presented. The histopathologic study allowed the identification of vascular and nervous tissue between the choroid and sclera, as it was seen on ultrasound examination.

Keywords: Choroid/pathology; Choroid/ultrasonography; Choroid hemorrhage; Choroid diseases; Case reports

\section{REFERÊNCIAS}

1. Brubaker RF, Pederson JE. Ciliochoroidal detachment. Surv Ophthalmol. 1983;27(5):281-9. Review.

2. Green WR. The uveal tract. In: Spencer WH, editor. Ophthalmic pathology: an atlas and textbook. $4^{\text {th }}$ ed. Philadelphia: W.B. Saunders; c1996. v.3. cap.10. p.1439-2120.

3. Chu TG, Green RL. Suprachoroidal hemorrhage. Surv Ophthalmol. 1999;43(6): 471-86.

4. Beyer CF, Peyman GA, Hill JM. Expulsive choroidal hemorrhage in rabbits. A histopathologic study. Arch Ophthalmol. 1989;107(11):1648-53

5. Wolter JR, Garfinkel RA. Ciliochoroidal effusion as precursor of suprachoroidal hemorrhage: a pathologic study. Ophthalmic Surg. 1988;19(5):344-9.

6. Byrne SF, Green RL. Ultrasound of the eye and orbit. St. Louis: Mosby Year Book; c1992.

7. Betinjane AJ, Carani JC. Ecografia ocular e orbitária. Série Atualidades Oftalmologia USP; v.6. São Paulo: Roca; 2003; p.33-41. 